\title{
Identification of the Anti-Aflatoxinogenic Activity of Micromeria graeca and Elucidation of Its Molecular Mechanism in Aspergillus flavus
}

\author{
Rhoda El Khoury ${ }^{1,2}$, Isaura Caceres ${ }^{1}$, Olivier Puel ${ }^{1}$, Sylviane Bailly ${ }^{1}$, Ali Atoui ${ }^{3}$, \\ Isabelle P. Oswald ${ }^{1}$, André El Khoury ${ }^{2}$ and Jean-Denis Bailly ${ }^{1, *}$ \\ 1 Toxalim, Université de Toulouse, INRA, ENVT, INP Purpan, UPS, Toulouse F-31027, France; \\ rhodakhoury@gmail.com (R.E.K.); isauracaceres@hotmail.com (I.C.); olivier.puel@inra.fr (O.P.); \\ s.bailly@envt.fr (S.B.); isabelle.oswald@inra.fr (I.P.O.) \\ 2 Laboratoire de Mycologie et Sécurité des Aliments (LMSA), Département des sciences de la vie et de la \\ terres - Biochimie, Faculté des Sciences, Université Saint-Joseph, P.O. Box 17-5208, Mar Mikhael Beirut 1104 \\ 2020 Lebanon; andre.khoury@usj.edu.lb \\ 3 Laboratory of Microbiology, Department of Natural Sciences and Earth, Faculty of Sciences I, \\ Lebanese University, Hadath Campus, P.O. Box 5, Beirut, Lebanon; a.atoui@cnrs.edu.lb \\ * Correspondence: jd.bailly@envt.fr; Tel.: +33-5-6119-3229
}

Academic Editor: Ting Zhou

Received: 18 January 2017; Accepted: 24 February 2017; Published: 1 March 2017

\begin{abstract}
Of all the food-contaminating mycotoxins, aflatoxins, and most notably aflatoxin $\mathrm{B}_{1}\left(\mathrm{AFB}_{1}\right)$, are found to be the most toxic and economically costly. Green farming is striving to replace fungicides and develop natural preventive strategies to minimize crop contamination by these toxic fungal metabolites. In this study, we demonstrated that an aqueous extract of the medicinal plant Micromeria graeca-known as hyssop-completely inhibits aflatoxin production by Aspergillus flavus without reducing fungal growth. The molecular inhibitory mechanism was explored by analyzing the expression of 61 genes, including 27 aflatoxin biosynthesis cluster genes and 34 secondary metabolism regulatory genes. This analysis revealed a three-fold down-regulation of aflR and aflS encoding the two internal cluster co-activators, resulting in a drastic repression of all aflatoxin biosynthesis genes. Hyssop also targeted fifteen regulatory genes, including $v e A$ and $m t f A$, two major global-regulating transcription factors. The effect of this extract is also linked to a transcriptomic variation of several genes required for the response to oxidative stress such as $m s n A, \operatorname{srr} A, \operatorname{cat} A, \operatorname{cat} 2, \operatorname{sod} 1, \operatorname{mnsod}$, and stuA. In conclusion, hyssop inhibits $\mathrm{AFB}_{1}$ synthesis at the transcriptomic level. This aqueous extract is a promising natural-based solution to control $\mathrm{AFB}_{1}$ contamination.
\end{abstract}

Keywords: Aflatoxin $\mathrm{B}_{1}$; Aspergillus flavus; hyssop; inhibition; oxidative stress

\section{Introduction}

Aspergillus flavus, a saprophytic fungus that develops on many crops including maize, oilseed, dried fruit, and spices [1], is the main producer of aflatoxin $\mathrm{B}_{1}\left(\mathrm{AFB}_{1}\right)$, the most potent naturally occurring carcinogen. $\mathrm{AFB}_{1}$ is associated with several pathologies mainly targeting the liver [2]. This mycotoxin also has major economic impacts as it contributes to considerable amounts of crop and livestock losses occur [3], endangering food and feed security. Globalization of food trade and global climate changes have further exacerbated the situation $[4,5]$.

Many methodologies have been developed to limit $\mathrm{AFB}_{1}$ contamination in crops. First, the implementation of good agricultural practices is undoubtedly a key factor to reduce undesirable growth of fungi. Fungal growth and mycotoxin production closely depend on temperature and humidity [6] and since these meteorological parameters are impossible to control, contamination 
cannot be completely avoided. The massive use of fungicides in crops over the last decades led to an accumulation of toxic chemical residues in food products but also in water and soil and resulted in the development of resistant pathogen populations [7].

Recent studies have pointed out the use of physio-chemical approaches to counteract aflatoxin contamination [8,9] while others were based on the detoxification properties or the protective physiological effect of bacterial metabolites or natural extracts used as feed supplements [10-13]. Although proven to be efficient, these approaches remain strictly restricted to animal feed. Nonetheless, such alternative strategies could be used at a much earlier phase, postharvest, to prevent aflatoxin production in crops. As an example, several bio-control approaches were developed relying on the use of microorganisms, such as lactic acid bacteria strains [14] or atoxinogenic fungi [15,16]. These strains displayed the ability to inhibit aflatoxin production or fungal growth to a certain extent $[17,18]$. Prevention strategies could also rely on the use of natural substances like plant extracts or essential oils. As plants grow, they produce many metabolites that serve as a defense against a number of environmental stresses. Therefore, plant extracts have long been studied as protective bioactive agents and it was demonstrated that some of them have antifungal or anti-toxinogenic properties $[19,20]$.

Micromeria graeca, commonly known as hyssop, is an herbaceous plant belonging to the Lamiaceae family. It is a widespread species in the Mediterranean basin and is frequently used for medicinal purposes and as a condiment [21]. The composition of essential oil, the toxicity, and the antimicrobial effect of different species of hyssop were previously described [22-27], but there is little data on the composition and toxicity of the aqueous extract of hyssop [21,28], and none on its antifungal or anti-mycotoxinogenic effect. The purpose of this study was to test the aqueous extract of $M$. graeca for its ability to prevent aflatoxin's biosynthesis. We observed that it inhibits $\mathrm{AFB}_{1}$ 's production by A. flavus strains without interfering with fungal growth. The molecular mechanism of action of this extract involved down-regulation of all the $\mathrm{AFB}_{1}$ biosynthetic cluster as well as modulation in the expression of 15 secondary metabolite regulating genes.

\section{Results}

\subsection{Effect of Aqueous Extract of Hyssop on the Production of $A F B_{1}$ and the Development of A. flavus}

When A. flavus strain NRRL 62477 was grown in a hyssop-supplemented medium, a dose-dependent decrease in $\mathrm{AFB}_{1}$ production was observed. The downward trend started at the lowest concentration $(0.0195 \mathrm{mg} / \mathrm{mL})$ and was statistically significant $(28.5 \%, p$-value 0.0032$)$ starting at $0.078 \mathrm{mg} / \mathrm{mL}$. Inhibition reached $99.2 \%$ at $10 \mathrm{mg} / \mathrm{mL}$ and $\mathrm{AFB}_{1}$ was no longer detectable at $15 \mathrm{mg} / \mathrm{mL}$ (Figure 1). Further experiments were then conducted supplementing the culture medium with $10 \mathrm{mg} / \mathrm{mL}$ of hyssop extract, this being the lowest to present a quasi-total inhibition of $\mathrm{AFB}_{1}$ synthesis.

At $10 \mathrm{mg} / \mathrm{mL}$, aflatoxin inhibition by hyssop was accompanied by a mild increase of the colony diameter ( $4.4 \pm 0.03$ vs. $4.25 \pm 0.03 \mathrm{~cm}$ for treated and control respectively, $p$-value 0.0213 ). However, no significant increase in the total spore count or in the spore density was observed following the addition of hyssop. Besides, no further change was observed in mycelium weights or for the germination delay in the presence of hyssop in the medium (Table 1). 


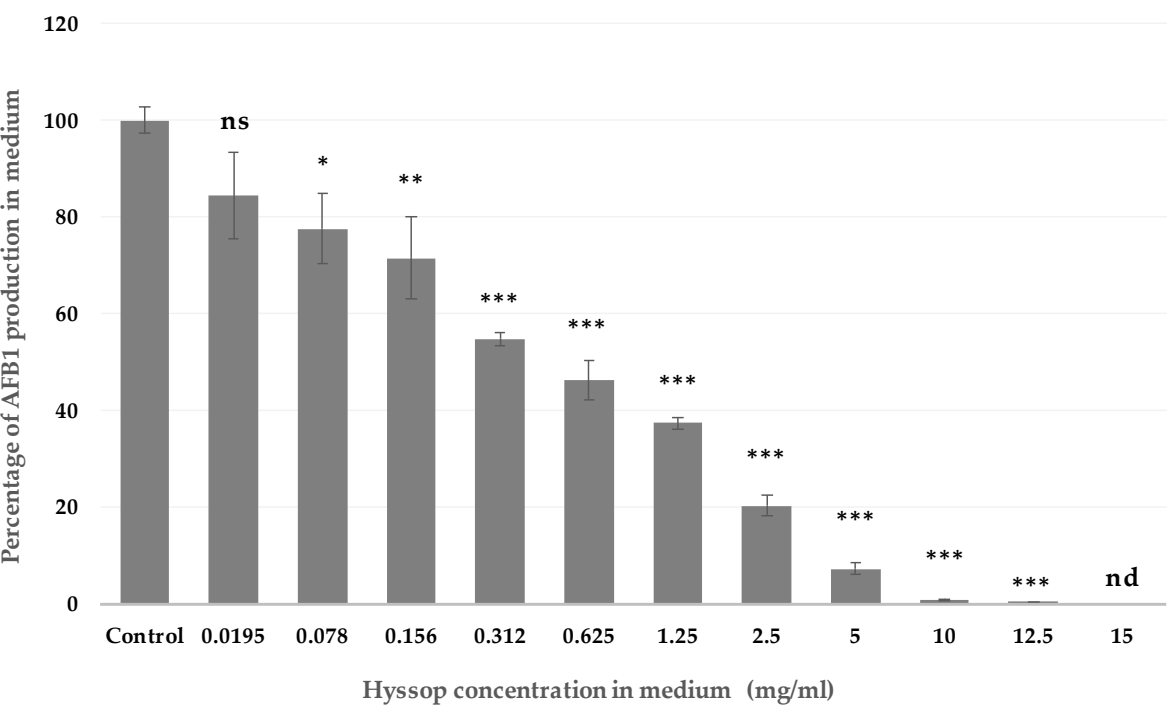

Figure 1. Aflatoxin $\mathrm{B}_{1}\left(\mathrm{AFB}_{1}\right)$ production as a function of hyssop concentration. Malt extract agar (MEA) medium was supplemented with increasing concentrations of hyssop extract ranging from 0.0195 to $15 \mathrm{mg} / \mathrm{mL}$ and cultivated at $27^{\circ} \mathrm{C}$, in the dark, for 8 days. $\mathrm{AFB}_{1}$ concentrations were quantified through HPLC/FLD. Results are expressed as mean $\% \pm \operatorname{SEM}(n=3)$. ns $=$ no significant changes; nd = not detectable; ${ }^{*} p$-value $<0.05 ;{ }^{* *} p$-value $<0.01 ;{ }^{* * *} p$-value $<0.001$.

Table 1. The effect of the addition of $10 \mathrm{mg} / \mathrm{mL}$ hyssop to the culture medium on the development of A. flavus (i) colony diameter was measured in length and width; (ii) weight was measured after a 48 h-drying at $60^{\circ} \mathrm{C}$; (iii) germinating conidia were counted by observation under stereo-microscope after $16 \mathrm{~h}$ incubation at $27^{\circ} \mathrm{C}$; (iv) total spore count is estimated following a complete wash of conidia and a Malassez-cell count of proper dilutions and (v) spore density was calculated based on the total spore count related to the colony surface. Results are expressed as mean $\pm \operatorname{SEM}(n=3)$.

\begin{tabular}{cccc}
\hline & Observed Parameters & MEA & $\begin{array}{c}\text { MEA + Hyssop } \\
\mathbf{1 0 ~} \mathbf{~ m g} / \mathbf{m L}\end{array}$ \\
\hline \multirow{2}{*}{ Growth } & Colony diameter $(\mathrm{cm})$ & $4.25 \pm 0.03$ & $4.4 \pm 0.03$ \\
& Mycelium dry weight $(\mathrm{g})$ & $0.16 \pm 0.03$ & $0.15 \pm 0.02$ \\
\multirow{3}{*}{ Sporulation } & Germinating conidia after $16 \mathrm{~h}(\%)$ & $96.5 \pm 8.5 \%$ & $101.5 \pm 4 \%$ \\
& Total spore count & $8.1 \times 10^{8} \pm 4.5 \times 10^{7}$ & $1.1 \times 10^{9} \pm 9.9 \times 10^{7}$ \\
& Spore density (conidia $\left./ \mathrm{cm}^{2}\right)$ & $5.7 \times 10^{7} \pm 2.6 \times 10^{6}$ & $7 \times 10^{7} \pm 5.6 \times 10^{6}$ \\
\hline
\end{tabular}

Following addition of hyssop in medium, $A$. flavus colonies presented numerous macro and microscopic modifications. The major noticeable macroscopic morphological change was the development of an abundant aerial mycelium covering the entire surface of the colony. This latter also displayed fasciculation on the edge. The presence of these numerous floccose tufts also increased the depth of the colony (Figure 2).

Under microscope, classic A. flavus structures were present in the basal mycelium of hyssop-treated cultures: long, coarse, un-branched conidiophores and radiate biseriate conidial heads. However, in the aerial mycelium, conidiophores, vesicles, and conidia presented an atypical morphology and organization: (1) an increased number of short conidiophores bearing small columnar heads in relation with the abundant aerial mycelium; (2) phialides developing anarchically on hyphae and on conidiophores in the absence of a vesicle; (3) and the presence of conidiophores with two, and less frequently three, sporulated vesicles (Figure 3). 


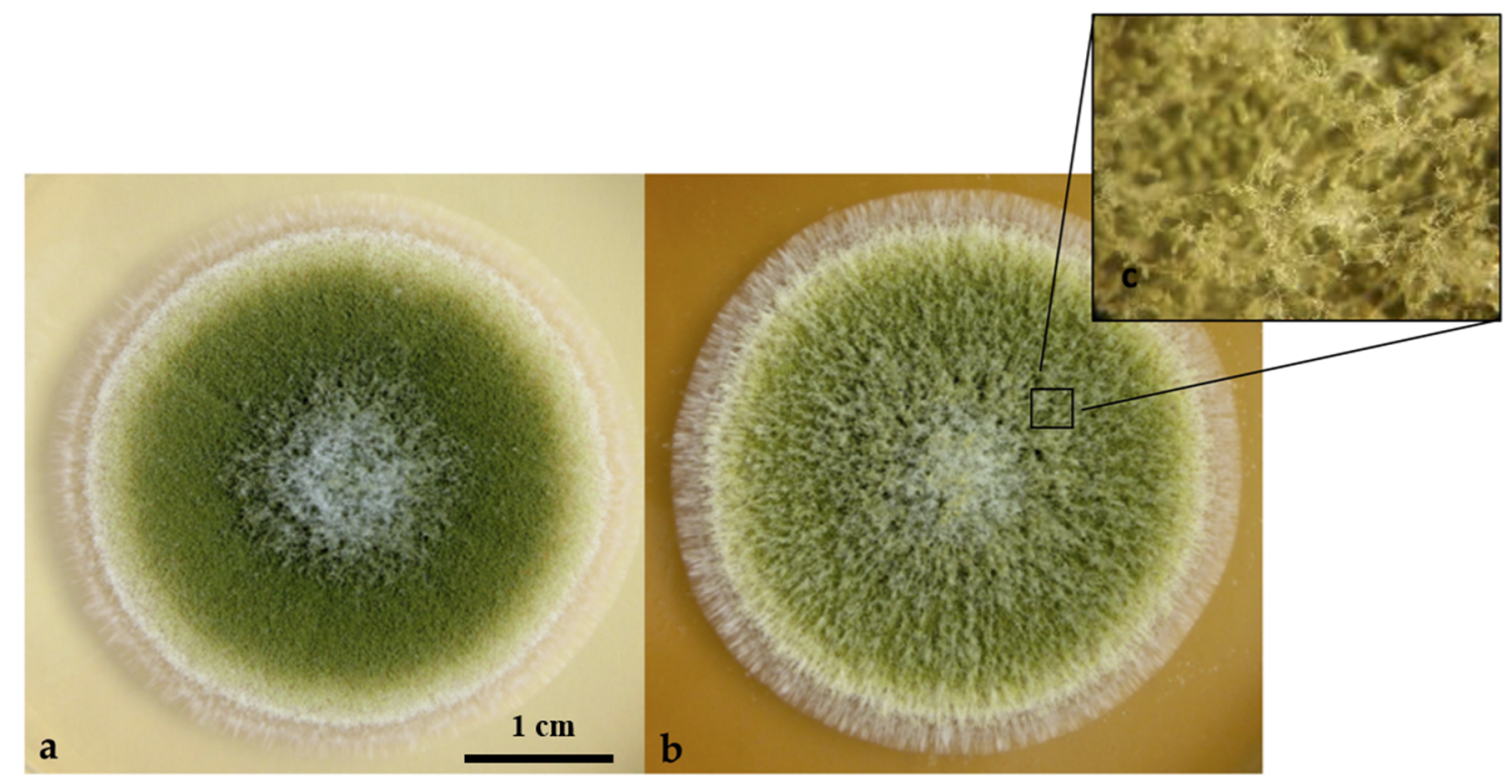

Figure 2. Phenotype of $A$. flavus strain NRRL62477 after four days of culture at $27^{\circ} \mathrm{C}$ in MEA medium or MEA medium supplemented with $10 \mathrm{mg} / \mathrm{mL}$ of hyssop aqueous solution. (a) Control culture grown on a regular MEA medium; (b) MEA medium was supplemented with $10 \mathrm{mg} / \mathrm{mL}$ of aqueous solution of hyssop; (c) Magnification of the aerial mycelium covering the hyssop treated culture.
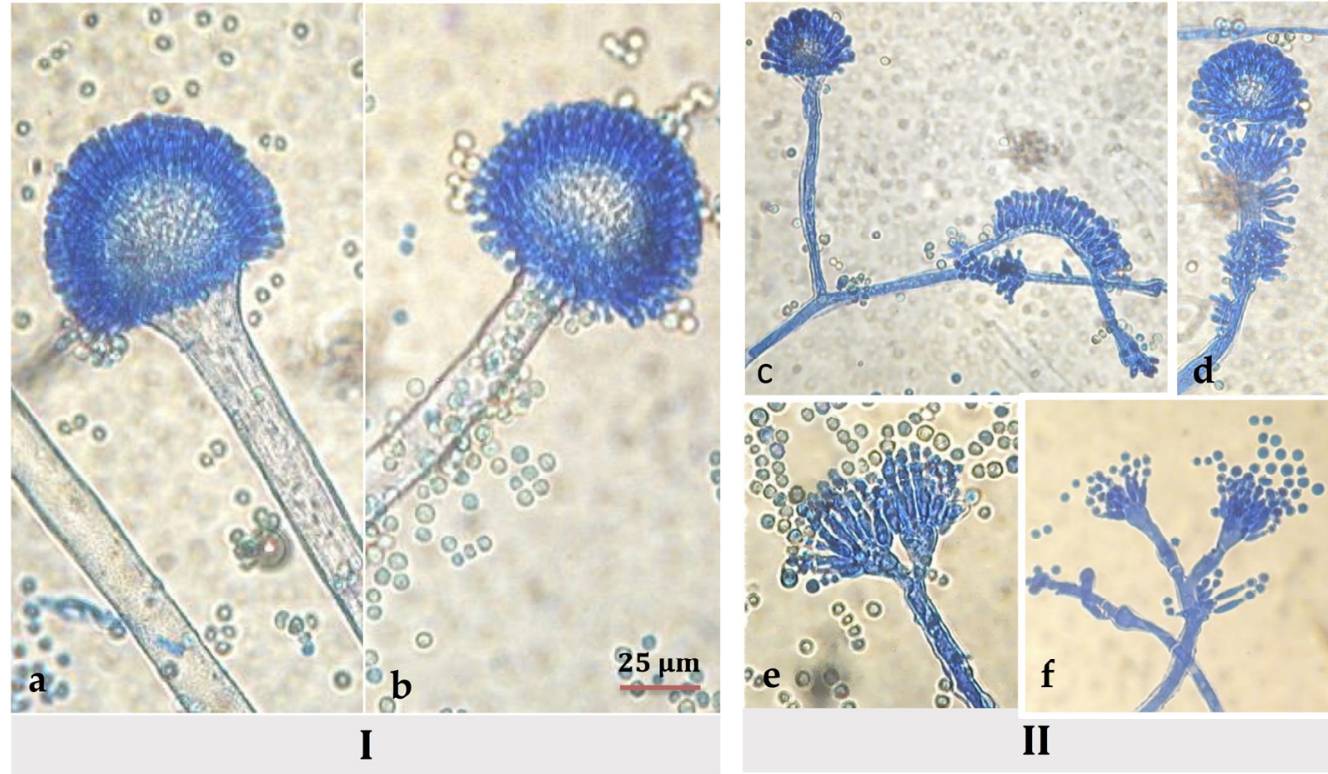

Figure 3. Microscopic views (x400) of A. flavus NRRL 62477 conidiophores in the (I) basal mycelium on (a) MEA medium and (b) MEA supplemented with $10 \mathrm{mg} / \mathrm{mL}$ of hyssop extract, and the (II) aerial mycelium showing the development of anarchic philalides when strain was grown on a hyssop-treated MEA medium; (c) and (d) development of anarchic philalides; (e) conidiophore bearing two vesicles and (f) presence of short conidiophores with columnar heads.

At the dose of $10 \mathrm{mg} / \mathrm{mL}$, we observed a $77.7 \%$ and $70.8 \%$ inhibition of the production of $\mathrm{AFB}_{1}$ in two other A. flavus strains (E28 and E71respectively), without alteration of fungal growth. Similar morphological changes were also observed for these two strains (data not shown). 


\subsection{Aqueous Extract of Hyssop Down-Regulated the Expression of $A F B_{1}$ Cluster Genes}

The biosynthesis of $\mathrm{AFB}_{1}$ is the result of a well-described cascade of more than 20 enzymatic reactions. This cascade is governed by 27 clustered genes encoding the corresponding enzymes as well as two internal regulators, AflR encoding a Gal4 zinc finger transcription factor and its co-activator AflS. The expression of all of these genes was analyzed in order to determine whether the inhibition of $\mathrm{AFB}_{1}$ synthesis occurred at a transcriptomic level. Inhibition of $\mathrm{AFB}_{1}$ production in hyssop-supplemented media was accompanied by a decrease in the expression of both of aflR and aflS genes by 3.2 and 2.8 times respectively ( $p$-value $<0.0001$ ). Apart from aflT (encoding a MFS-family transporter), which is not regulated by the AflR/AflS complex [29] and was down regulated only by 2.3 times ( $p$-value $<0.0001$ ), the expression of the remaining cluster genes was severely repressed (Figure 4).

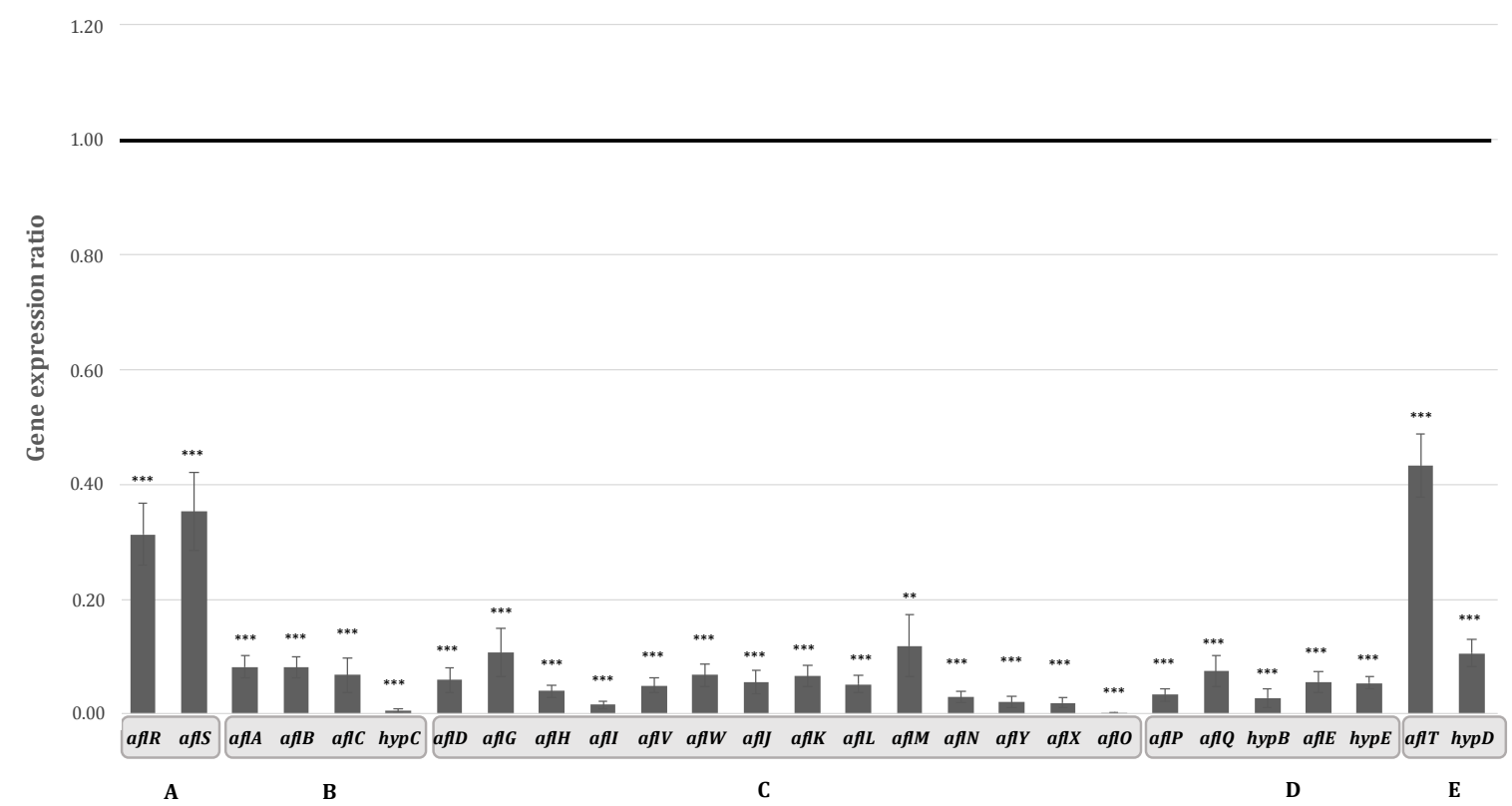

Figure 4. Expression of genes belonging to $\mathrm{AFB}_{1}$ cluster genes in the presence of $10 \mathrm{mg} / \mathrm{mL}$ of hyssop aqueous extract; (A) internal cluster regulators (B) genes involved in the earlier steps of $\mathrm{AFB}_{1}$ enzymatic cascade leading to the formation of norsolorinic acid (C) genes involved in the middle steps of the $\mathrm{AFB}_{1}$ enzymatic cascade converting norsolorinic acid into sterigmatocystin (D) genes involved in the final steps of the cascade leading to $\mathrm{AFB}_{1}$ synthesis $(\mathrm{E})$ genes with uncharacterized functions. Black line represents the expression level of control. ${ }^{* *} p$-value $<0.01 ;{ }^{* * *} p$-value $<0.001$.

Genes undergoing the most drastic inhibitions were $h y p C$, aflI, and aflO, encoding enzymes respectively intervening at the beginning, middle, and end of the biosynthetic pathway and with corresponding fold-changes of $167.2,60.7$, and 468.8 with $p$-values $<0.001$. For the genes encoding enzymes involved in the first steps of the cascade leading to the polyketide structure, aflA, aflB, and aflC, expression was decreased by $12.2,12.3$, and 14.7 respectively. The least impacted genes were aflM, aflG, and hypD with expression levels decreased by 8.4, 9.3, and 9.4 times respectively. For the remaining $\mathrm{AFB}_{1}$ cluster genes, the same downward trend was observed with expression levels decreased by 14 to 50 folds (Supplementary Material Table S1). This repression of the entire aflatoxin gene cluster could then be directly linked to the inhibition of the production of this mycotoxin. 


\subsection{Transcriptomic Effect of Hyssop Extract on the Expression of Genes Coding for Regulators of Secondary Metabolites}

The expression of $\mathrm{AFB}_{1}$ cluster genes is subjected to the control exerted by regulatory factors encoded by genes outside of the cluster. In order to investigate a possible genetic relationship between those regulators and the transcriptional inhibition of $\mathrm{AFB}_{1}$ cluster genes after the addition of hyssop extract, we conducted a study on the regulatory network affecting secondary metabolism that includes 34 genes involved in several fungal functional pathways. Among these, a total of 15 genes involved in diverse cellular mechanisms were modulated by adding hyssop to the culture medium (Figure 5). The modulated genes could be grouped in five categories based on their cellular functions in other ascomycetes [30]. The first one includes global regulating factors such as veA, $m t f A, n s d C$ that were affected with expression levels respectively increased by 3.8, 1.9, and 1.5 folds ( $p$-values $<0.0001,0.0001$ and 0.0122). Secondly, genes encoding enzymes involved in cellular protection from oxidative stress such as superoxide dismutases ( $\operatorname{sod} 1$ and $m n s o d$ ) and catalases (cat $A$ and cat2) had their expression decreased by 1.6, 2, 2.2, and 3 folds respectively ( $p$-values $0.013,0.0007,0.004$, and $<0.0001$ ). Other genes intervening in the oxidative stress response and encoding transcription factors, notably $m s n A$ and $\operatorname{sr} A$, had their expression levels increased by 3.2 and 1.4 times with $p$-values of 0.0126 and 0.0017 , respectively. The third category involves gprK and $g p r H$, encoding G-protein receptors involved in relaying external signals with gprK expression increased by 2 folds ( $p$-value $<0.0001)$ and $g p r H$ decreased by 2.1 folds ( $p$-value 0.0006). Moreover, $p p o C$ encoding a fatty acid dioxygenase involved in oxylipin production also presented an expression decreasing by 1.5 times ( $p$-value 0.003$)$. The conidial developmental factor stuA whose expression increased by 1.8 times ( $p$-value 0.0012 ) constitutes the fourth category. Finally, two genes encoding environmentally influenced transcription factors whose expression is respectively modulated by nitrogen and medium $\mathrm{pH}$, are $\mathrm{A}$ and $\mathrm{pac} C$ were also triggered by the addition of hyssop in the medium and their expression levels were respectively increased by 1.7 and 1.6 folds with $p$-values of 0.0215 and $<0.0001$.

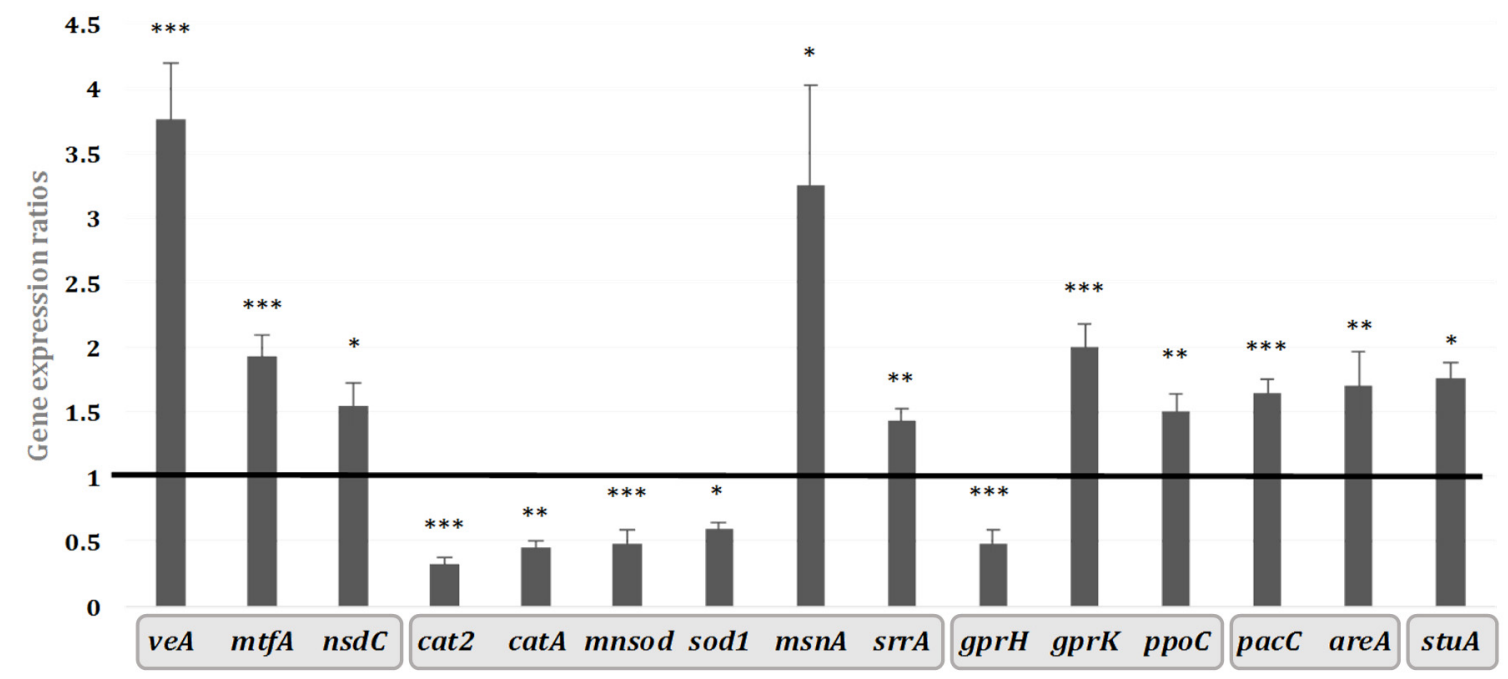

Figure 5. Schematic representation of gene expression ratios of the different regulatory genes affected upon $10 \mathrm{mg} / \mathrm{mL}$ hyssop supplementation of MEA media. Genes are grouped into the five categories described above. The black line represents the expression level of genes in control cultures. ${ }^{*} p$-value $<0.05 ;{ }^{* *} p$-value $<0.01 ;{ }^{* * *} p$-value $<0.001$. 


\section{Discussion}

3.1. Hyssop Leads to an Inhibition of $A F B_{1}$ Synthesis in A. flavus by a Transcriptomic Regulation of $A F B_{1}$ Cluster Genes

The inhibition of $\mathrm{AFB}_{1}$ synthesis was dose-dependent (Figure 1) and the same impact was observed using several strains of A. flavus. Another recent study by Omidpanah et al. (2015) [31] pointed out that some aqueous extracts including thyme and mint had fungicidal effect on $A$. flavus at concentrations of 0.2 and $0.8 \mathrm{mg} / \mathrm{mL}$ respectively, yet without determining aflatoxin inhibition at any of the concentration range used. At a comparable concentration of $0.625 \mathrm{mg} / \mathrm{mL}$, hyssop's extract was able to inhibit the production of aflatoxin by $52 \%$ without restraining the growth of $A$. flavus. A slight trend for an increase in total spore count and density was observed upon addition of hyssop, but these results remain statistically non-significant and do not affect the anti-aflatoxinogenic property of the extract.

$\mathrm{AFB}_{1}$ biosynthesis in aflatoxinogenic fungi is the result of a coordinated cascade of enzymatic reactions. The enzymes catalyzing these reactions are encoded by 27 genes and grouped into a cluster located in the telomeric region of the 3rd chromosome of aflatoxinogenic species [32]. The function of almost all of these genes was elucidated and described in previous works [33-35]. We demonstrated that $\mathrm{AFB}_{1}$ inhibition in $A$. flavus by $M$. graeca extract is consistent with a drastic repression of all $\mathrm{AFB}_{1}$ cluster genes following a significant decrease in the expression levels of the two internal cluster regulators aflR and aflS (previously annotated as aflJ) (Figure 4). Furthermore, the down-regulation of these two latter genes in AF-repressive conditions has been previously described as associated with the repression of the entire AF cluster genes [36]. It could also be noted that the inhibition level of the cluster genes does not depend on their chronological intervention in the enzymatic cascade leading to $\mathrm{AFB}_{1}$ synthesis, contrary to what has been described for other anti-aflatoxinogenic agents such as eugenol [30].

\subsection{The Implication of VeA and MtfA: Two Leading Transcriptional Regulators}

VeA is a global regulating transcription factor involved in primary and secondary metabolism [37] and recruiting other factors such as LaeA and VelB to form the trimeric velvet complex. The activity of this complex affects fungal development, conidiation, and secondary metabolism [38]. In hyssop-treated cultures, transcripts of $l a e A, v e l B$, and $v o s A$, the latter being an interacting partner of velB [39], were not affected (Table S1). This result further highlights the independent role of VeA in multiple other cellular mechanisms [40]. The presence of VeA is necessary for the expression of secondary metabolite genes; however, it can also act as a repressor of some of these genes and thus inhibit the production of the concerned metabolite. VeA is essential for the transcription of AF cluster genes, including the transcription factor aflR and others (aflD, aflM, and aflP) regulating production of aflatoxin. Deletion of the veA gene led to the repression of $\mathrm{AFB}_{1}$ cluster genes in $A$. flavus [41]. However, according to our current study and to another recent one [30], a repression of all $\mathrm{AFB}_{1}$ cluster genes can also coincide with a veA-over-expression profile (Figure 5). Such is the case of penicillin, produced by $A$. nidulans where an OE:ve $A$ led to the repression of $a c v A$, the penicillin biosynthesis gene and subsequent inhibition of penicillin production [42].

VeA can also interact with another conserved global transcription factor, MtfA. The latter has a major role in regulating the development and the secondary metabolism in filamentous fungi [43] and it is linked to $\mathrm{AFB}_{1}$ 's biosynthesis as well as to aflR's expression. An over-expression of $m t f A$ in $A$. flavus has drastically inhibited the production of $\mathrm{AFB}_{1}$ following a down-regulation of aflR, whereas the effect of an $m t f A$ deletion was less important [44]. The concurring over-expression of $m t f A$ and $v e A$ in our conditions (Figure 5), which further highlights the interaction between these two factors, could then be responsible for down-regulating AF-cluster genes and inhibiting the production of aflatoxin. 


\subsection{Implication of Other Regulatory Factors in AF Inhibition by M. graeca-Hyssop Extract}

Stressful environmental conditions may lead fungi to establish several defense lines to limit cellular damage. For example, when subjected to oxidative stress, fungi might respond by producing secondary metabolites such as aflatoxins. The oxidative stress generated by enhanced lipid peroxidation and the free radical generation was proven to be a prerequisite for aflatoxin production in A. parasiticus [45]. Moreover, the anti-aflatoxinogenic effect of antioxidant agents, such as eugenol, seems to be linked to an alleviation of oxidative stress and lipid peroxidation as well as a modulation of the expression of a number of genes involved in the oxidative stress response [30,46].

It has been demonstrated that VeA contributes to a positive transcriptomic modulation of stress-tolerance genes such as $m s n A$ and $s r r A$ under induced oxidative stress conditions [39]. The expression of these two transcription factors is then highly dependent on that of veA. Therefore, their over-expression in a hyssop-treated medium might be the outcome of an over-expressed veA (Figure 5). The developmental factor StuA has also been associated to stress-response in fungi, yet there isn't a clear view on its contribution [47]. However, its dependence on $m s n A$ was shown since its expression levels were modulated in A. flavus as well as in A. parasiticus $m s n A$-deleted strains [48]. MsnA is also known for regulating the expression of the catalases (CAT)- and superoxide dismutases (SOD)-encoding genes [48]. Those antioxidant enzymes along with aflatoxin formation are suggested as part of the fungus defense mechanism against reactive oxygen species (ROS) damages [49]. When the medium was supplemented with $M$. graeca extract, $A$. flavus responded by decreasing the expression of SOD- and CAT-encoding genes such as sod1, mnsod, cat $A$ and cat 2 as levels of $m s n A$ increased thus resulting in an AF-biosynthesis repression, possibly related to an alleviation of environmental oxidative stress.

Two other regulatory factors that were not linked to oxidative stress were also modulated by hyssop's addition to medium. The first regulator is $\mathrm{PacC}$, which is a $\mathrm{pH}$-dependent factor whose over-expression in aflatoxin-repressive conditions is to be investigated. In fact, $\mathrm{PaCC}$ is usually activated under alkaline conditions [50] whereas hyssop addition does not change the $\mathrm{pH}$ of the medium (data not shown).

The second regulatory factor is NsdC, known to be a developmental regulator whose alteration causes several morphological aberrances such as shorter-stipe conidiophores presenting abnormal conidial-head formations. Similar to VeA, NsdC modulation could participate to the morphological modifications observed in hyssop-treated cultures (Figure 3). It has also been linked to aflatoxin cluster-gene expression [51] as well as being a global regulator of secondary metabolism [52]. More data is yet to be collected on the individual and possibly collaborative roles of both of these factors in the regulation of secondary metabolism.

\subsection{Morphological Modifications of Conidiophores and Vesicles of A. flavus in Hyssop-Supplemented Media}

Besides its role in secondary metabolite regulation, VeA is also a developmental factor in regulating morphogenesis as alterations in its expression levels can result in morphological abnormalities. For example, a reduction in fungal aerial hyphae was noted in both A. flavus and Fusarium graminaerum veA deleted strains $[41,53]$. Therefore, the modulation of veA expression could contribute to morphological abnormalities observed upon hyssop exposure (Figure 3 ).

Furthermore, a single previous study has described the modification of the aerial hyphae in an AF-inhibiting profile in $A$. parasiticus in the presence of n-decyl aldehyde, a corn-derived volatile compound [54]. However, another study conducted on A. flavus mutant strains described the appearance of morphological abnormalities, notably on phialide formation, associated to a cessation of $\mathrm{AFB}_{1}$ production [51].

Alterations in morphology, such as the development of aerial hyphae, were also associated to an imbalance in the G-protein signal transduction pathway $[55,56]$. This pathway is governed by the binding of signaling molecule to G-protein coupled receptors (GPCR) such as those encoded by $g p r K$ and $g p r H$, both affected by the addition of hyssop to the media (Figure 5), and tuned by 
regulators of the G-protein signaling cascade (RGS), whose roles and implication in $\mathrm{AFB}_{1}$ synthesis are being investigated in A. flavus [57]. G-protein signaling pathway is also linked to oxylipins that are hormonal-like signaling molecules [58] produced by fatty-acid-oxygenases such as PpoC. Moreover, oxylipins regulation has also been described as VeA-dependent [37]. However, fungal signal perception and transduction pathways are a very complex loop due to the diversity of signals that might initiate them and most importantly to the numerous acting factors involved downstream. Since M. graeca extract is a complex extract containing many signal-provoking agents such as polysaccharides, amino acids, minerals, phenolic compounds and many others, it remains possible that morphological modifications have no direct link to $\mathrm{AFB}_{1}$ 's inhibition.

\section{Conclusions}

This study demonstrates the efficiency of $M$. graeca aqueous extract in limiting $\mathrm{AFB}_{1}$ contamination without altering fungal growth. Such an effect could ensure food safety without affecting biodiversity. Indeed, A. flavus is a very competitive crop-contaminating agent; therefore, the use of fungistatic agents could favor the emergence of other, possibly uncontrollable microorganisms. According to our results, inhibition by hyssop extract occurs at a transcriptomic level as expression ratios of all of aflatoxin cluster-genes were severely decreased. Nonetheless, hyssop extract triggered a response in several fungal cellular mechanisms including cellular signaling, global transcription factors, and conidial development, as well as factors acting in the oxidative stress response. Massive transcriptomic analyses, such as RNAseq or Microarray assays, would be a good complement to this study since they could provide a broader vision of cellular functions affected by the addition of hyssop to the medium. Nonetheless, being as complex as it is, this extract may shelter several bioactive compounds [59] contributing in a complementary way to its anti-aflatoxinogenic activity. To ascertain more accurately the inhibitory mechanism of action, the content of this extract needs to be deciphered in order to determine and purify its active molecules as well as the inhibition extent of each of the isolated compounds.

\section{Materials and Methods}

\subsection{Solvents and Standards}

All solvents were HPLC grade and purchased from ThermoScientific Fisher (Villebon-Sur-Yvette, France). Lyophilized aflatoxin $B_{1}$ standard was purchased from Sigma Aldrich (St. Louis, MO, USA). Stock solutions of each of the standards were prepared in methanol and stored at $4{ }^{\circ} \mathrm{C}$ in the dark. Calibration curves were prepared beforehand by diluting stock solutions with mobile phase used for HPLC analysis.

\subsection{Preparation of the Aqueous Solution of Hyssop}

Dried hyssop (M. graeca) was commercially purchased from Tyr, Lebanon. Hyssop species was kindly confirmed by Prof. Marc Beyrouthy (Department of Agricultural Sciences, USEK-Lebanon). Leaves were ground with an electrical grinder and ten grams of ground hyssop were added to $80 \mathrm{~mL}$ of bi-distilled water and placed on a horizontal shaking table at $220 \mathrm{rpm}$ for $24 \mathrm{~h}$. Extracts were then filtered through cotton gauze before being centrifuged for $10 \mathrm{~min}$ at $3500 \mathrm{rpm}$. Filtrates were centrifuged once again, at $4700 \mathrm{rpm}$ for $30 \mathrm{~min}$ and autoclaved at $121^{\circ} \mathrm{C}$ for $15 \mathrm{~min}$. Final sterile extracts were stored at $+4{ }^{\circ} \mathrm{C}$ until their use.

\subsection{Fungal Strains and Growth Conditions}

A referenced toxinogenic Aspergillus flavus strain NRRL 62477 isolated from paprika samples harvested from a Moroccan market [59] was used to evaluate aflatoxin inhibition by aqueous solution of hyssop as well as the molecular mechanism of inhibition. Further analysis of total aflatoxin inhibition by the aqueous hyssop solution was conducted on two other A. flavus strains (E28 and E71) that 
were previously isolated from white pepper and paprika samples from Morocco [60]. Strains were cultivated on a malt extract agar (MEA) medium (30 g malt extract and $15 \mathrm{~g}$ agar-agar per liter) (Biokar Diagnostics, Allone, France), supplemented at $2 \% v / v$ with the autoclaved aqueous hyssop solution, whereas $2 \% v / v$ water-supplemented media were used for control cultures. The media for RNA isolation and dry weight measurement were layered with $8.5 \mathrm{~cm}$ diameter cellophane disks (Hutchinson, Chalette-sur-Loing, France) before inoculation in order to allow separation of mycelium from the culture medium. Spore suspensions were prepared in Tween $80(0.05 \%$ in water) from a one-week-old MEA culture. Spores were counted on a Malassez cell and $10^{3}$ spores were inoculated in the center of the medium. Cultures destined for RNA isolation were incubated in 6 replicates per condition for 4 days. For $\mathrm{AFB}_{1}$ quantification assays, cultures were incubated for 8 days and were in triplicates. All cultures were incubated at $27^{\circ} \mathrm{C}$. The media pH was measured before and after inoculation and after incubation using a H199161 food pH-meter (Hanna Instruments, Tanneries, France).

\subsection{Examination of Cultural Parameters}

\subsubsection{Effect on Growth}

The final growth mean was estimated by the measurement of culture diameters in length and width at day 4 .

\subsubsection{Mycelium Dry Weight}

Following a four-day incubation period, cellophane disks were peeled off and placed in new petri dishes that were incubated for $48 \mathrm{~h}$ at $60^{\circ} \mathrm{C}$. Dried mycelium films were allowed to cool in a desiccator before being weighed on an analytical balance. Final weight was calculated by subtracting the mean weight of four desiccated control cellophane disks.

\subsubsection{Total Spore Quantification}

Colonies were cut out of MEA media, $1 \mathrm{~mm}$ beyond the mycelium border, placed in a stomacher bag with $50 \mathrm{~mL}$ of Tween $0.05 \%$ and spores were gently manually scraped off of culture without tearing the media. The bag was then placed in a stomacher for $90 \mathrm{~s}$. The supernatant was filtered through cotton gauze that was then rinsed with $3 \times 20 \mathrm{~mL}$ Tween $0.05 \%$. Spore solutions were homogenized by thorough vortex and subsequent dilutions were prepared in Tween $0.05 \%$ for counting on a Malassez cell in order to determine the total spore count (SC). Spore density (SD) was calculated as $S D=S C /\left(\pi r^{2}\right), r=$ average colony radius.

\subsubsection{Delay to Germination}

Two hundred spores were inoculated in the center of the media and germinating spores were counted after a $16-\mathrm{h}$ incubation period at $27^{\circ} \mathrm{C}$ by stereo-microscopic examination.

\subsubsection{Fungal Morphological Features}

Macroscopic (e.g., color of conidial areas, thallus margin and texture, aspect of conidial heads and colony reverse) and microscopic (e.g., conidiophore, shape of vesicles, number of sterigmata, shape of conidia and ornamentation) characters were observed under stereomicroscope SZX9-X12-120 (Olympus, Rungis, France) and optical microscope CX41-X400 and X1000 (Olympus, Rungis, France) respectively.

\subsection{RNA Isolation and Reverse Transcription}

Cellophane disks along with the four-day mycelium were peeled off from the medium, finely grinded with liquid nitrogen and a maximum of $100 \mathrm{mg}$ were used for total RNA purification through a RNeasy Plus Minikit (Qiagen, Hilden, Germany), which includes an on-column genomic 
DNA clean-up, following the manufacturer's instructions. RNA integrity and purity were checked with agarose gel electrophoresis and a NanoDrop ND1000 (Labtech, Palaiseau, France) that also determined its concentration. First-strand cDNA synthesis reaction was primed using RevertAid Reverse Transcriptase (MBI Fermentas, UK), RNase Inhibitor (Applied Biosystems, Warrington, UK) and an anchored oligo(dT) Bys 3' Primer (5'-GCTGTCAACGATACGCTAACGTAACGGCATGAC AGTGTTTTTTTTTTTTTTTTT- $3^{\prime}$ ). An RT minus sample, where no reverse transcriptase reaction takes place, and a sterile water sample were added as negative controls in order to verify the absence of undesirable genomic DNA contamination and primer complementation, respectively.

\subsection{Real-Time PCR Expression Profile Analysis of Genes Regulating $A F B_{1}$ Biosynthesis in A. flavus}

The genome of A. flavus strain NRRL 3357 (GenBank accession number EQ963478) served as a matrix for all of the primer used in this study. Gene selection and the corresponding primer pair sequences were adapted from a previous work [29] and primer sequences of the stuA gene (AFLA_046990) were added in this study (stuA_F: GATAAACGGAACCAAACTGCTCAA; stuA_R: CACGCTCAAATGGGATCCAA ). In total, the expression of 61 genes was simultaneously analyzed, 27 of which corresponded to the $\mathrm{AFB}_{1}$ cluster and 34 to regulatory factors. Regulatory factors were grouped into 6 categories: (1) environmental transcription factors (Area, CreA, MeaB and PacC); (2) oxidative stress response factors (AtfA, AP-1, CatA, Cat2, MnSOD, MsnA, and SrrA); (3) the velvet complex (LaeA, VeA, VelB and VosA); (4) factors belonging to different cellular signaling families such as the Ras-family (RasA), the G-protein signaling family (FadA and FlbA) as well as the G-protein receptors (GprK, GprA, GprH, GprP, and GprG) and oxylipin enzymes (PpoA, PpoB, and PpoC); (5) regulators of development and conidiation (FluG, BrlA, StuA, and AbaA) and (6) global secondary-metabolism-regulating transcription factors (NsdC, MtfA, and Fcr3). Primer pairs design was based on the coding sequence of the corresponding genes, with at least one of the primers extending on an exon/exon junction in order to avoid undesirable genomic DNA amplification. Primer-dimers or self-complementarities were evaluated using the PrimerExpress 2.0 software (Applied Biosystems, Courtaboeuf, France). All primers were synthesized by Sigma Aldrich (Saint-Quentin Fallavier, France). Following RNA extractions and reverse transcriptase reactions, real-time PCR assays were performed on $15 \mathrm{ng}$ cDNA in a $5 \mu \mathrm{L}$ reaction volume per well, using Power SYBR ${ }^{\circledR}$ Green PCR Master Mix (Applied Biosystems, Warrington, UK) as a fluorescent dye for cDNA quantification. Master mixes and diluted cDNA samples were prepared separately on 96-well Framestar Jupe plates (Dominique Dutscher, Issy-les-Moulineaux, France) and mixed in 384-well plates by an Agilent Bravo Automated Liquid Handling Platform (Agilent Technologies, Santa Clara, CA, USA). All real time amplification reactions were carried out on a ViiA7 Real-Time PCR System (Applied Biosystems, Warrington, UK), as described by Tannous et al. [61].

\subsection{Aflatoxin Extraction and HPLC Quantification}

Media of four- and eight-day cultures were entirely retrieved and their $\mathrm{AFB}_{1}$ content determined after extraction with 25 and $40 \mathrm{~mL}$ chloroform respectively. Extracts were held for $2 \mathrm{~h}$ on a horizontal shaking table at $200 \mathrm{rpm}$ and were then filtered through a Whatman 1PS phase separator filter (GE Healthcare Life Sciences, Vélizy-Villacoublay, France, $150 \mathrm{~mm}$ diameter). Filtrates were evaporated to dryness and dissolved in $1 \mathrm{~mL}$ of a water-acetonitrile-methanol mixture (65:17.5:17.5; $v / v / v)$. Extracts were filtered using $0.45 \mu \mathrm{m}$ porosity disks (Thermo Scientific Fisher, Villebon-Sur-Yvette, France) before analysis. HPLC analysis was performed using a Dionex Ultimate 3000 UHPLC (Thermo Scientific, France) using a $125 \times 2 \mathrm{~mm}, 5 \mu \mathrm{m}, 100 \AA$, Luna ${ }^{\circledR} \mathrm{C} 18(2)$ LC column (Phenomenex, Torrance, CA, USA). Aflatoxins were separated using the program described by Fu, Huang, \& Min, 2008, with minor modifications [62]. A mixture of water (acidified with $0.2 \%$ acetic acid)-acetonitrile (79:21, $v / v)$ is eluent A and methanol is eluent B. Separation program consists of a 30 min A:B (82.5:17.5) isocratic flow at $0.2 \mathrm{~mL} / \mathrm{min}$. Aflatoxins were detected using a fluorescent detector at wavelengths of $365 / 430 \mathrm{~nm}$ (excitation/emission). UV Spectra were confirmed by an additional diode array 
detector (DAD) coupled to the apparatus. Sample concentrations were calculated based on a standard calibration curve.

\subsection{Statistics}

All experiments were performed in triplicate. For gene expression assays, six biological replicates were used each time for each gene. Data presented for the dose-dependent effect of hyssop extract were analyzed using a One-way ANOVA followed by a post hoc Dunnett's test $(\alpha=0.05)$ and conducted with XLSTAT (Addinsoft, Paris). Gene expression and growth and sporulation data were analyzed using Student's t-test in Excel statistics. Differences were considered statistically significant when $p$-value was lower than 0.05 .

Supplementary Materials: The following are available online at www.mdpi.com/2072-6651/9/3/87/s1, Table S1: Gene expression ratios of $\mathrm{AFB}_{1}$ cluster genes upon hyssop addition. Ratios are obtained in comparison to control values.

Acknowledgments: The authors would like to thank Marc Beyrouthy (Department of Agricultural Sciences, USEK-Lebanon) for identifying the species of the hyssop plant used in this study and Françoise Michaud (National Veterinary School of Toulouse) and Amy Smith for English editing. This work was funded by the projects Aflafree (ANR-11-ALID-0003), Aflared (joint project, 001-2012 STDF-AIRD), and ToxinFree (Campus France PHC cèdre 32763). The authors would also like to thank the Agence Nationale de la Recherche (ANR) and the Research Council of Saint-Joseph University (Lebanon), the two organizations funding the doctoral studies of Rhoda El Khoury. Doctoral studies of Isaura Caceres were funded by the Consejo Nacional de Ciencia y Tecnología (CONACYT) México. The funders had no role in study design, data collection and analysis, decision to publish, or preparation of the manuscript.

Author Contributions: Isabelle P. Oswald, Olivier Puel, Jean-Denis Bailly, Ali Atoui, and André El Khoury conceived, supervised, and designed the experiments. Rhoda El Khoury and Isaura Caceres performed the experiments, analyzed the data, and contributed to experiment design. Sylviane Bailly performed morphological analysis. Rhoda El Khoury and Jean-Denis Bailly wrote the paper.

Conflicts of Interest: The authors declare no conflict of interest. The funding sponsors had no role in the design of the study; in the collection, analyses, or interpretation of data; in the writing of the manuscript; or in the decision to publish the results.

\section{References}

1. Klich, M.A. Aspergillus flavus: The major producer of aflatoxin. Mol. Plant Pathol. 2007, 8, 713-722. [CrossRef] [PubMed]

2. Cano, P.; Puel, O.; Oswald, I.P. Mycotoxins: Fungal Secondary Metabolites with Toxic Properties. In Fungi Applications and Management Strategies; Deshmukh, S.K., Misra, J.K., Tewari, J.P., Papp, T., Eds.; CRC Press: Boca Raton, FL, USA, 2016; pp. 318-371.

3. Bryden, W.L. Mycotoxin contamination of the feed supply chain: Implications for animal productivity and feed security. Anim. Feed Sci. Technol. 2012, 173, 134-158. [CrossRef]

4. Wu, F.; Guclu, H. Aflatoxin regulations in a network of global maize trade. PLoS ONE 2012, 7, e45151. [CrossRef] [PubMed]

5. Medina, A.; Rodriguez, A.; Magan, N. Effect of climate change on Aspergillus flavus and aflatoxin $\mathrm{B}_{1}$ production. Front. Microbiol. 2014, 5, 348. [CrossRef] [PubMed]

6. Magan, N.; Aldred, D. Post-harvest control strategies: Minimizing mycotoxins in the food chain. Int. J. Food Microbiol. 2007, 119, 131-139. [CrossRef] [PubMed]

7. Da Cruz Cabral, L.; Fernández Pinto, V.; Patriarca, A. Application of plant derived compounds to control fungal spoilage and mycotoxin production in foods. Int. J. Food Microbiol. 2013, 166, 1-14. [CrossRef] [PubMed]

8. Mao, J.; He, B.; Zhang, L.; Li, P.; Zhang, Q.; Ding, X.; Zhang, W. A Structure identification and toxicity assessment of the degradation products of aflatoxin $\mathrm{B}_{1}$ in peanut oil under UV irradiation. Toxins (Basel) 2016, 8, 332. [CrossRef] [PubMed]

9. Diao, E.; Li, X.; Zhang, Z.; Ma, W.; Ji, N.; Dong, H. Ultraviolet irradiation detoxification of aflatoxins. Trends Food Sci. Technol. 2015, 42, 64-69. [CrossRef] 
10. Zhang, L.; Ma, Q.; Ma, S.; Zhang, J.; Jia, R.; Ji, C.; Zhao, L. Ameliorating effects of Bacillus subtilis ANSB060 on growth performance, antioxidant functions, and aflatoxin residues in ducks fed diets contaminated with aflatoxins. Toxins (Basel) 2016, 9, 1. [CrossRef] [PubMed]

11. Zhang, N.-Y.; Qi, M.; Zhao, L.; Zhu, M.-K.; Guo, J.; Liu, J.; Gu, C.-Q.; Rajput, S.; Krumm, C.; Qi, D.-S.; et al. Curcumin prevents aflatoxin $\mathrm{B}_{1}$ hepatoxicity by inhibition of cytochrome $\mathrm{P} 450$ isozymes in chick liver. Toxins (Basel) 2016, 8, 327. [CrossRef] [PubMed]

12. Xu, L.; Eisa Ahmed, M.; Sangare, L.; Zhao, Y.; Selvaraj, J.; Xing, F.; Wang, Y.; Yang, H.; Liu, Y. Novel aflatoxin-degrading enzyme from Bacillus shackletonii L7. Toxins (Basel) 2017, 9, 36. [CrossRef] [PubMed]

13. Dellafiora, L.; Galaverna, G.; Reverberi, M.; Dall'Asta, C. Degradation of aflatoxins by means of laccases from Trametes versicolor: An in silico insight. Toxins (Basel) 2017, 9, 17. [CrossRef] [PubMed]

14. Saladino, F.; Luz, C.; Manyes, L.; Fernández-Franzón, M.; Meca, G. In vitro antifungal activity of lactic acid bacteria against mycotoxigenic fungi and their application in loaf bread shelf life improvement. Food Control 2016, 67, 273-277. [CrossRef]

15. Mauro, A.; Battilani, P.; Cotty, P.J. Atoxigenic Aspergillus flavus endemic to Italy for biocontrol of aflatoxins in maize. Biocontrol 2015, 60, 125-134. [CrossRef]

16. Odhiambo, B.O.; Murage, H.; Wagara, I.N. Screening for Atoxigenic Aspergillus Species and Evaluating their Inhibitory Potential against Growth and Sporulation of Aflatoxigenic Aspergillus Species. Egert. J. Sci. Technol. 2014, 14, 61-80.

17. Dalié, D.K.D.; Deschamps, A.M.; Richard-Forget, F. Lactic acid bacteria-Potential for control of mould growth and mycotoxins: A review. Food Control 2010, 21, 370-380. [CrossRef]

18. Jane, C.; Kiprop, E.K.; Mwamburi, L.A. Biocontrol of Aflatoxins in Corn using Atoxigenic Aspergillus flavus: Review. Int. J. Sci. Res. 2014, 3, 1954-1958.

19. Kohiyama, C.Y.; Yamamoto Ribeiro, M.M.; Mossini, S.A.G.; Bando, E.; Bomfim, N.D.S.; Nerilo, S.B.; Rocha, G.H.O.; Grespan, R.; Mikcha, J.M.G.; Machinski, M. Antifungal properties and inhibitory effects upon aflatoxin production of Thymus vulgaris L. by Aspergillus flavus Link. Food Chem. 2015, 173, 1006-1010. [CrossRef] [PubMed]

20. Chulze, S.N. Strategies to reduce mycotoxin levels in maize during storage: A review. Food Addit. Contam. Part A Chem. Anal. Control. Expo. Risk Assess. 2010, 27, 651-657. [CrossRef] [PubMed]

21. Abu-Gharbieh, E.; Shehab, N.G.; Khan, S.A. Anti-inflammatory and gastroprotective activities of the aqueous extract of Micromeria fruticosa (L.) Druce ssp Serpyllifolia in mice. Pak. J. Pharm. Sci. 2013, 26, 799-803. [PubMed]

22. Džamić, A.M.; Soković, M.D.; Novaković, M.; Jadranin, M.; Ristić, M.S.; Tešević, V.; Marin, P.D. Composition, antifungal and antioxidant properties of Hyssopus officinalis L. subsp. pilifer (Pant.) Murb. essential oil and deodorized extracts. Ind. Crops Prod. 2013, 51, 401-407. [CrossRef]

23. Michalczyk, M.; Macura, R.; Tesarowicz, I.; Banaś, J. Effect of adding essential oils of coriander (Coriandrum sativum L.) and hyssop (Hyssopus officinalis L.) on the shelf life of ground beef. Meat Sci. 2012, 90, 842-850. [CrossRef] [PubMed]

24. Soylu, E.M.; Kurt, S.; Soylu, S. In vitro and in vivo antifungal activities of the essential oils of various plants against tomato grey mould disease agent Botrytis cinerea. Int. J. Food Microbiol. 2010, 143, 183-189. [CrossRef] [PubMed]

25. Tisserand, R. Essential oil safety II. metabolism, neurotoxicity, reproductive toxicity. Int. J. Aromather. 1996, 7, 26-29. [CrossRef]

26. Alwan, S.; El Omari, K.; Soufi, H.; Zreika, S.; Sukarieh, I.; Chihib, N.-E.; Jama, C.; Hamze, M. Evaluation of the antibacterial activity of Micromeria barbata in Lebanon. J. Essent. Oil Bear. Plants 2016, 19, 321-327. [CrossRef]

27. Formisano, C.; Oliviero, F.; Rigano, D.; Saab, A.M.; Senatore, F. Chemical composition of essential oils and in vitro antioxidant properties of extracts and essential oils of Calamintha origanifolia and Micromeria myrtifolia, two Lamiaceae from the Lebanon flora. Ind. Crops Prod. 2014, 62, 405-411. [CrossRef]

28. Skotti, E.; Anastasaki, E.; Kanellou, G.; Polissiou, M.; Tarantilis, P.A. Total phenolic content, antioxidant activity and toxicity of aqueous extracts from selected Greek medicinal and aromatic plants. Ind. Crops Prod. 2014, 53, 46-54. [CrossRef]

29. Chang, P.-K.; Yu, J.; Yu, J.-H. aflT, a MFS transporter-encoding gene located in the aflatoxin gene cluster, does not have a significant role in aflatoxin secretion. Fungal Genet. Biol. 2004, 41, 911-920. [CrossRef] [PubMed] 
30. Caceres, I.; El Khoury, R.; Medina, Á.; Lippi, Y.; Naylies, C.; Atoui, A.; El Khoury, A.; Oswald, I.P.; Bailly, J.-D.; Puel, O. Deciphering the anti-aflatoxinogenic properties of eugenol using a large-scale q-PCR approach. Toxins (Basel) 2016, 8, 123. [CrossRef] [PubMed]

31. Omidpanah, S.; Sadeghi, H.; Mohamadian, M.; Manayi, A. Evaluation of antifungal activity of aqueous extracts of some medicinal plants against Aspergillus flavus, pistachio aflatoxin producing fungus in vitro. Drug Dev. Ther. 2015, 6, 66-69.

32. Georgianna, D.R.; Payne, G.A. Genetic regulation of aflatoxin biosynthesis: From gene to genome. Fungal Genet. Biol. 2009, 46, 113-125. [CrossRef] [PubMed]

33. Yu, J.; Chang, P.-K.; Ehrlich, K.C.; Bhatnagar, D.; Cleveland, T.E.; Payne, G.A.; Linz, J.E.; Woloshuk, C.P.; Bennett, J.W. Clustered pathway genes in aflatoxin biosynthesis. Appl. Environ. Microbiol. 2004, 70, 1253-1262. [CrossRef] [PubMed]

34. Ehrlich, K.C. Predicted roles of the uncharacterized clustered genes in aflatoxin biosynthesis. Toxins (Basel) 2009, 1, 37-58. [CrossRef] [PubMed]

35. Ehrlich, K.C.; Yu, J.; Cotty, P.J. Aflatoxin biosynthesis gene clusters and flanking regions. J. Appl. Microbiol. 2005, 99, 518-527. [CrossRef] [PubMed]

36. Holmes, R.A.; Boston, R.S.; Payne, G.A. Diverse inhibitors of aflatoxin biosynthesis. Appl. Microbiol. Biotechnol. 2008, 78, 559-572. [CrossRef] [PubMed]

37. Calvo, A.M. The VeA regulatory system and its role in morphological and chemical development in fungi. Fungal Genet. Biol. 2008, 45, 1053-1061. [CrossRef] [PubMed]

38. Bayram, O.; Braus, G.H. Coordination of secondary metabolism and development in fungi: The velvet family of regulatory proteins. FEMS Microbiol. Rev. 2012, 36, 1-24. [CrossRef] [PubMed]

39. Bayram, O.; Krappmann, S.; Ni, M.; Bok, J.W.; Helmstaedt, K.; Valerius, O.; Braus-Stromeyer, S.; Kwon, N.-J.; Keller, N.P.; Yu, J.-H.; et al. VelB/VeA/LaeA complex coordinates light signal with fungal development and secondary metabolism. Science 2008, 320, 1504-1506. [CrossRef] [PubMed]

40. Baidya, S.; Duran, R.M.; Lohmar, J.M.; Harris-Coward, P.Y.; Cary, J.W.; Hong, S.-Y.; Roze, L.V.; Linz, J.E.; Calvo, A.M. VeA is associated with the response to oxidative stress in the aflatoxin producer Aspergillus flavus. Eukaryot. Cell 2014, 13, 1095-1103. [CrossRef] [PubMed]

41. Duran, R.M.; Cary, J.W.; Calvo, A.M. Production of cyclopiazonic acid, aflatrem, and aflatoxin by Aspergillus flavus is regulated by veA, a gene necessary for sclerotial formation. Appl. Microbiol. Biotechnol. 2007, 73, 1158-1168. [CrossRef] [PubMed]

42. Sprote, P.; Brakhage, A.A. The light-dependent regulator velvet A of Aspergillus nidulans acts as a repressor of the penicillin biosynthesis. Arch. Microbiol 2007, 188, 69-79. [CrossRef] [PubMed]

43. Ramamoorthy, V.; Dhingra, S.; Kincaid, A.; Shantappa, S.; Feng, X.; Calvo, A.M. The putative $\mathrm{C} 2 \mathrm{H} 2$ transcription factor MtfA is a novel regulator of secondary metabolism and morphogenesis in Aspergillus nidulans. PLoS ONE 2013, 8, e74122. [CrossRef] [PubMed]

44. Zhuang, Z.; Lohmar, J.M.; Satterlee, T.; Cary, J.W.; Calvo, A.M. The master transcription factor $m t f A$ governs aflatoxin production, morphological development and pathogenicity in the fungus Aspergillus flavus. Toxins (Basel) 2016, 8, 29. [CrossRef] [PubMed]

45. Jayashree, T.; Subramanyam, C. Oxidative stress as a prerequisite for aflatoxin production by Aspergillus parasiticus. Free Radic. Biol. Med. 2000, 29, 981-985. [CrossRef]

46. Jayashree, T.; Subramanyam, C. Antiaflatoxigenic activity of eugenol is due to inhibition of lipid peroxidation. Lett. Appl. Microbiol. 1999, 28, 179-183. [CrossRef] [PubMed]

47. Hong, S.-Y.; Roze, L.V.; Linz, J.E. Oxidative stress-related transcription factors in the regulation of secondary metabolism. Toxins (Basel) 2013, 5, 683-702. [CrossRef] [PubMed]

48. Chang, P.-K.P.; Scharfenstein, L.L.L.; Luo, M.; Mahoney, N.; Molyneux, R.J.; Yu, J.; Brown, R.L.; Campbell, B.C. Loss of $m s n A$, a putative stress regulatory gene, in Aspergillus parasiticus and Aspergillus flavus increased production of conidia, aflatoxins and kojic acid. Toxins (Basel) 2011, 3, 82-104. [CrossRef]

49. Hong, S.-Y.; Roze, L.V.; Wee, J.; Linz, J.E. Evidence that a transcription factor regulatory network coordinates oxidative stress response and secondary metabolism in aspergilli. Microbiologyopen 2013, 2, 144-160. [CrossRef] [PubMed]

50. Ke, R.; Haynes, K.; Stark, J. Modelling the activation of alkaline $\mathrm{pH}$ response transcription factor PacC in Aspergillus nidulans: Involvement of a negative feedback loop. J. Theor. Biol. 2013, 326, 11-20. [CrossRef] [PubMed] 
51. Cary, J.W.; Harris-Coward, P.Y.; Ehrlich, K.C.; Mack, B.M.; Kale, S.P.; Larey, C.; Calvo, A.M. NsdC and NsdD affect Aspergillus flavus morphogenesis and aflatoxin production. Eukaryot. Cell 2012, 11, 1104-1111. [CrossRef] [PubMed]

52. Gilbert, M.K.; Mack, B.M.; Wei, Q.; Bland, J.M.; Bhatnagar, D.; Cary, J.W. RNA sequencing of an nsdC mutant reveals global regulation of secondary metabolic gene clusters in Aspergillus flavus. Microbiol. Res. 2015, 182, 150-161. [CrossRef] [PubMed]

53. Jiang, J.; Liu, X.; Yin, Y.; Ma, Z. Involvement of a velvet protein FgVeA in the regulation of asexual development, lipid and secondary metabolisms and virulence in Fusarium graminearum. PLoS ONE 2011, 6, e28291. [CrossRef] [PubMed]

54. Wright, M.S.; Greene-Mcdowelle, D.M.; Zeringue, H.J.; Bhatnagar, D.; Cleveland, T.E. Effects of volatile aldehydes from Aspergillus-resistant varieties of corn on Aspergillus parasiticus growth and aflatoxin biosynthesis. Toxicon 2000, 38, 1215-1223. [CrossRef]

55. Yang, Q.; Borkovich, K.A. Mutational activation of a G $\alpha(\mathrm{i})$ causes uncontrolled proliferation of aerial hyphae and increased sensitivity to heat and oxidative stress in Neurospora crassa. Genetics 1999, 151, 107-117. [PubMed]

56. Han, K.H.; Seo, J.A.; Yu, J.H. Regulators of G-protein signalling in Aspergillus nidulans: RgsA downregulates stress response and stimulates asexual sporulation through attentuation of GanB $(\mathrm{G} \alpha)$ signalling. Mol. Microbiol. 2004, 53, 529-540. [CrossRef] [PubMed]

57. Affeldt, K.; Carrig, J.; Amare, M.G.; Keller, N. Global survey of canonical Aspergillus flavus G protein-coupled receptors. MBio 2014, 5, 1501-1514. [CrossRef] [PubMed]

58. Brodhagen, M.; Keller, N.P. Signalling pathways connecting mycotoxin production and sporulation. Mol. Plant Pathol. 2006, 7, 285-301. [CrossRef] [PubMed]

59. Atoui, A.K.; Mansouri, A.; Boskou, G.; Kefalas, P. Tea and herbal infusions: Their antioxidant activity and phenolic profile. Food Chem. 2005, 89, 27-36. [CrossRef]

60. EL Mahgubi, A.; Bailly, S.; Tadrist, S.; Querin, A.; Ouadia, A.; Oswald, I.P.; Bailly, J.-D. Distribution and toxigenicity of Aspergillus section Flavi in spices marketed in Morocco. Food Control 2013, 32, 143-148. [CrossRef]

61. Tannous, J.; El Khoury, R.; Snini, S.P.; Lippi, Y.; El Khoury, A.; Atoui, A.; Lteif, R.; Oswald, I.P.; Puel, O. Sequencing, physical organization and kinetic expression of the patulin biosynthetic gene cluster from Penicillium expansum. Int. J. Food Microbiol. 2014, 189, 51-60. [CrossRef] [PubMed]

62. Fu, Z.; Huang, X.; Min, S. Rapid determination of aflatoxins in corn and peanuts. J. Chromatogr. A 2008, 1209, 271-274. [CrossRef] [PubMed]

(C) 2017 by the authors. Licensee MDPI, Basel, Switzerland. This article is an open access article distributed under the terms and conditions of the Creative Commons Attribution (CC BY) license (http:/ / creativecommons.org/licenses/by/4.0/). 